\title{
Differential HSC70 expression during asexual development of Neurospora crassa
}

\author{
Franco Fracella, Carl Scholle, Andreas Kallies, Thomas Hafker, \\ Torsten Schroder and Ludger Rensing
}

\author{
Author for correspondence: Ludger Rensing. Tel: +49 421218 2126. Fax: +494212184042. \\ e-mail : rensing@uni-bremen.de
}

Institute of Cell Biology, Biochemistry and Biotechnology, University of Bremen, PO Box 3304 40, D-28334 Bremen, Germany

\begin{abstract}
The constitutive and the heat-shock-induced expression of members of heatshock protein families changed during vegetative development and conidiation of Neurospora crassa as determined by two-dimensional gel electrophoresis. Western blot and ELISA analyses revealed the highest amounts of the constitutive heat-shock protein 70 (HSC70) in conidiating aerial hyphae and dormant conidia. During conidial germination the amount of HSC70 decreased and subsequently increased during vegetative growth. Stationary mycelia and young aerial hyphae exhibited the lowest HSC70 level. The stationary-phase-dependent decrease in HSC70 was accompanied by a concomitant increase in its nuclear localization, whereas no significant changes in the amount of nuclear HSC70 were found during aerial hyphae development. The CAMP content during aerial hyphae development was inversely correlated with that of HSC70. To examine possible causal relations between HSC70 expression and CAMP content, the adenylate-cyclase-deficient mutant crisp (cr-1) was analysed, which exhibits low concentrations of endogenous CAMP. This mutant, however, showed a lower constitutive HSC70 level, compared to the bdA strain. Treatment of the bd strain and cr-1 mutant with $20 \mu \mathrm{M}$ 8-bromo-cAMP did not result in significant changes of the constitutive HSC7O level, but in the level of heat-induced HSC/HSP70. In a developmental mutant (acon-2) which is defective in a differentiation step toward conidiation, the expression of HSC7O in aerial hyphae was delayed until the first proconidial chains were observed. It is concluded that the differential expression of HSC/HSP70 does not depend on different nuclear levels of HSC70 or on changes in CAMP concentrations, but rather on developmental genes controlling conidiation.
\end{abstract}

Keywords: heat shock, HSC70/HSP70, Neurospora crassa, developmental regulation, conidiation

\section{INTRODUCTION}

Exposure of cells to stress conditions such as a sudden increase in temperature dramatically alters the patterns of gene expression. The synthesis of several specific proteins, the heat-shock (or stress) proteins (HSPs), is increased or induced against a background of reduced synthesis of most house-keeping cellular proteins (Morimoto et al., 1994). The heat shock response of $N$. crassa and some of the heat-shock genes or HSPs

Abbreviations: CRE, CAMP-responsive element; HSC, constitutive heatshock protein; HSE, heat-shock element; HSF, heat-shock transcription factor; HSP, heat-shock protein. involved are well-characterized (Plesofsky-Vig \& Brambl, 1985a, b, 1990; Vassilev et al., 1992; Roychowdhury et al., 1992; Machwe \& Kapoor 1993; Fracella et al., 1993; Kapoor et al., 1995).

Even under normal physiological conditions, cells maintain a rather high level of constitutive (or cognate) isoforms of stress proteins (HSC), because they perform important functions as 'molecular chaperones' in the folding, transport and repair of other proteins (Hartl et al., 1994; Becker \& Craig, 1994). The constitutive expression of some HSPs, particularly of HSC70, changes during the development of several organisms (Hightower \& Nover, 1991). In fungi, the sporulation process, in particular, was found to be associated with a 
higher expression of heat-shock genes (Kurtz \& Lindquist, 1984; Bonato et al., 1987; Patterson \& Kapoor, 1995). Except for two indirect hints (PlesofskyVig \& Brambl, 1985a, b), however, no data exist about the constitutive expression of HSCs during the asexual development of $N$. crassa, which consists of dormant and germinating conidia, hyphal growth, aerial hyphae formation and conidiation (for a review see Russo \& Pandit, 1992). This study focused particularly on aerial hyphae formation and conidiation, because the molecular genetics of these processes are already well analysed (Matsuyama et al., 1974; Roberts et al., 1988; Springer \& Yanofsky, 1989). After detecting differences in the expression of HSPs during these developmental processes, this work concentrated on the putative mechanisms behind these differences.

The rapid and transient heat-shock gene expression in response to stress is under the control of a specific heatshock transcription factor (HSF). In most organisms, HSF acts as a trimer which binds to one or multiple repeats of the heat-shock response element (HSE) only upon heat shock (Bienz \& Pelham, 1987; Morimoto et al., 1992). The yeast HSF binds to HSEs already before heat shock and is phosphorylated in a stress-dependent manner (Giardina \& Lis, 1995; Sorger et al., 1987; Sorger \& Pelham, 1988). This was observed to be similar in Neurospora (U. Meyer \& L. Rensing, unpublished).

The basal or constitutive HSC expression is believed to also depend on $\operatorname{HSF}(\mathrm{s})$ together with other not clearly defined factors and elements. Analysis of the HSC70 promoter region of certain species suggests a complex regulation pattern involving elements that may interact with serum response factor-, stimulating protein 1-, transcription factor IID-, CAT transcription factor- and activating transcription factor/CREB-like factors (Wu et al., 1987; Williams et al., 1989). A further transcription factor involved in the regulation of HSC/HSP70 synthesis binds close to HSEs and was named 'constitutive heat-shock element binding factor' (CHBF, Lin et al., 1993). Despite the presence of ATF/CRE-like elements a regulatory role of cAMP is still controversial in most species (Choi et al., 1991; Engelberg et al., 1994; Kiang et al., 1994; Pizurki \& Polla, 1994). A possible role of cAMP in the differential hsp gene expression was therefore examined.

cAMP seems to play a central role in the development and differentiation of many lower eukaryotes, including $N$. crassa. In this organism, aerial hyphae formation depends on higher cAMP concentrations, as deduced from differentiation defects observed in the adenylatecyclase-deficient mutant $c r-1$, which exhibits reduced levels of endogenous cAMP (Terenzi et al., 1974). This mutant, on the other hand, shows constitutive thermotolerance (Cruz et al., 1988), indicating a link between low cAMP levels and the expression of stress proteins. In analogous mutants of Saccharomyces cerevisiae (cyr1$2)$, this phenotype is conferred by the elevated constitutive expression of some hsp genes (Iida \& Yahara, 1984). cAMP may act not only on the expression of $h s p$ genes directly by way of CRE-like sequences but also by influencing the transport of proteins and transcription factors into the nucleus.

To analyse possible relations between the cAMP level and the constitutive expression of HSC70 in N. crassa we measured the cAMP content and HSC70 levels during asexual development. The results showed that the HSC70 levels and the cAMP contents were inversely correlated during most developmental stages. Addition of cAMP, however, had little effect on the amounts of constitutive HSC70. In contrast, heat-shock-induced HSP70 synthesis was considerably changed in the presence of external cAMP. Since the amount of HSC70 may also be influenced by developmental transcription factors, a developmental mutant of $N$. crassa (acon-2) which is defective in early conidiation processes (Springer \& Yanofsky, 1989) was also analysed. In this mutant, HSC70 expression and conidiation were both reduced and delayed.

\section{METHODS}

Strains, culture conditions and sample preparation. The wild-type (wt) and the mutant strains band (bdA), crisp (cr-1) and acon-2 of $N$. crassa were obtained from the Fungal Genetic Stock Center (Kansas City, KS, USA). The $b d A$ mutant shows a particularly clear circadian conidiation pattern but other properties of the mutant are very similar to the wild-type. The wt strain and $b d A$ were compared with respect to the constitutive and induced $h s c / h s p 70$ expression (Fig. 2). Since there were only small differences $b d A$ was used in the subsequent experiments. The $c r-1$ mutant is adenylate cyclase-deficient and therefore exhibits reduced concentrations of endogenous cAMP (Terenzi et al., 1974). The acon2 mutant is defective in an early developmental step of conidia formation, the minor constriction budding (for a review see Russo \& Pandit, 1992).

Dormant conidia were raised on Horowitz minimal medium (Horowitz, 1947) in Petri dishes and harvested dry by tapping on dishes held bottom up. Germinating conidia were obtained from liquid cultures containing Vogel's minimal medium (Vogel, 1956) supplemented with $1 \mathrm{mM} \mathrm{CaCl}_{2}$ and $2 \%$ sucrose $(\mathrm{w} / \mathrm{v})$ incubated in constant light at $25^{\circ} \mathrm{C}$ on a rotary shaker. After the indicated times, cells were harvested by centrifugation. Dormant conidia and germlings were broken in a French press by the addition of PBS $(0 \cdot 145 \mathrm{M} \mathrm{NaCl}, 8 \mathrm{mM}$ $\mathrm{Na}_{2} \mathrm{HPO}_{4}, 1.5 \mathrm{mM} \mathrm{KH_{2 }} \mathrm{PO}_{4}$ ) containing $10 \mathrm{mM}$ ATP and $10 \mathrm{mM} \mathrm{MgCl} 2$. Mycelia were raised at $25^{\circ} \mathrm{C}$ under the same conditions as germinating conidia and harvested by filtration. Aerial hyphae were harvested by scraping from the Horowitz medium. Mycelia (vegetative hyphae) and aerial hyphae were broken by sonication in PBS containing $10 \mathrm{mM}$ ATP and $10 \mathrm{mM} \mathrm{MgCl}{ }_{2}$.

For isolation of cytoplasm and nuclei a modified method of Loros \& Dunlap (1991) was used. All procedures were performed at $4^{\circ} \mathrm{C}$. Mycelia were homogenized in a Vibrogen mill containing $25 \mathrm{~g}$ glass pearls of $2 \mathrm{~mm}$ diameter. Glass pearls and mycelia were mixed with ice-cold nuclear buffer I ( $1 \mathrm{M}$ sorbitol, $7 \%$ (w/v) Ficoll 400, $20 \%$ (v/v) glycerol, $5 \mathrm{mM}$ $\mathrm{MgCl}_{2}, 10 \mathrm{mM} \mathrm{CaCl}, 1 \%$ (v/v) surfynol and $3 \mathrm{mM}$ dithioerythritol (DTE), $\mathrm{pH} 7 \cdot 5$ ) and mycelia homogenized by three $45 \mathrm{~s}$ pulses in the Vibrogen mill. The homogenate was then centrifuged at $1500 \mathrm{~g}$ for $10 \mathrm{~min}$ and the supernatant again centrifuged at $15000 \mathrm{~g}$ for $10 \mathrm{~min}$. 
The pellet contains the nuclei which were then washed by nuclear buffer II $(5 \mathrm{mM}$ Tris/ $\mathrm{HCl}, 5 \mathrm{mM} \mathrm{MgCl}, 20 \%$ (v/v) glycerol, $3 \mathrm{mM} \mathrm{DTE}, \mathrm{pH} 7 \cdot 5)$. The relative purity of the nuclear fraction was analysed by fluorescence microscopy after staining with 4-diamidino-2-phenylindole-dihydro chloride (DAPI). Using PAGE and Coomassie staining the nuclear fraction was further tested for the presence of histones. They were present in significant amounts. Electron microscopic inspection of the nuclear fraction, however, also revealed fragmented nuclei. The nuclear fraction was dissolved in Laemmli sample buffer $(2 \%, \mathrm{w} / \mathrm{v}$, SDS, $10 \%, \mathrm{v} / \mathrm{v}$, glycerol, $10 \mathrm{mM}$ 2-mercaptoethanol, $0.1 \mathrm{M}$ Tris, $\mathrm{pH} \mathrm{6.8),}$ homogenized by sonication (10 pulses) and boiled for $2 \mathrm{~min}$.

The supernatant was again centrifuged at $15000 \mathrm{~g}$ for $1 \mathrm{~h}$. The resulting supernatant, the cytoplasmic fraction, was dialysed against dialysis buffer $(5 \mathrm{mM}$ Tris/ $\mathrm{HCl}, \mathrm{pH} 7 \cdot 5)$, lyophilized and resuspended in Laemmli sample buffer for electrophoresis.

Heat shock and CAMP treatment. For heat-shock treatment of mycelia, the culture flasks or dishes were incubated at $45^{\circ} \mathrm{C}$ in a waterbath for the times indicated. For cAMP treatment $20 \mu \mathrm{M} 8$-bromo-cAMP was continuously present in the culture medium during the production of conidiospores and during subsequent conidial germination and growth of a mycelium (treatment schedule indicated in Fig. 6, 8b-bdA-8b). Another treatment schedule involved presence of 8-bromo-cAMP only during germination and growth of mycelia, indicated as bdA$8 \mathrm{~b}$ in Fig. 6. In the case of heat shock, 8-bromo-cAMP was present during the heat treatment.

Radioactive labelling, electrophoresis and fluorography. Germinating conidia, mycelia or aerial hyphae were labelled with L- $\left[{ }^{35} \mathrm{~S}\right]$ methionine $\left(370 \mathrm{kBq} \mathrm{ml}^{-1}\right.$, specific activity $29.6 \mathrm{TBq} \mathrm{mmol}^{-1}$; Amersham) for $1 \mathrm{~h}$ at either 25 or $45^{\circ} \mathrm{C}$. The labelled proteins were then separated by two-dimensional gel electrophoresis as described by O'Farrell (1975). Fluorography of the gels was carried out according to the method described by Bonner \& Laskey (1974). Quantitative evaluation of the two-dimensional gels was performed by measuring 25 spots densitometrically and determining the relative density of individual HSPs as a percentage of the total density of the 25 spots. One-dimensional SDS-PAGE was performed on $10 \%$ acrylamide $-0.3 \%$ bisacrylamide ( $w / v)$ gels (Laemmli, 1970).

Antibody preparation. Rabbits were immunized with primary injections of $30 \mu \mathrm{g}$ dialysed and lyophilized HSC70 isolated from N. crassa (Fracella et al., 1993) in $0.25 \mathrm{ml} \mathrm{PBS} \mathrm{(pH} \mathrm{7.5)} \mathrm{in}$ a 1:1 mixture with Freund's complete adjuvant (Calbiochem) distributed to two subcutaneous sites on the back. Booster injections of $15 \mu \mathrm{g} \mathrm{HSC70}$ were given at $14 \mathrm{~d}$ intervals after primary injection in an identical manner except that incomplete Freund's adjuvant (Calbiochem) was used. For affinity-purification the antiserum was applied to columns with immobilized HSC70. Specific antibodies were eluted with $0.1 \mathrm{M}$ glycine ( $\mathrm{pH} 2 \cdot 7)$, and neutralized and diluted $(1: 1000)$ in $0.2 \%(\mathrm{v} / \mathrm{v})$ Tween 20 containing PBS (PBST-0.2).

Western blot analysis. For Western blotting, identical concentrations of total protein ( $5 \mu \mathrm{g}$ per lane) were separated by one-dimensional $10 \%$ SDS-PAGE (Laemmli, 1970) and transferred to a nitrocellulose membrane using a TransBlot Cell (Bio-Rad; Towbin et al., 1979). The blots were blocked with PBST -0.2 for $1 \mathrm{~h}$ at $25^{\circ} \mathrm{C}$. After removal of the blocking solution, primary antibody diluted in PBST $(1: 1000)$ was added and left for $1 \mathrm{~h}$ at $25^{\circ} \mathrm{C}$. Subsequently, the blots were washed with PBST $-0 \cdot 2$. Secondary antibody (goat anti-rabbit IgG alkaline phosphatase conjugate; Bio-Rad) diluted in PBST-0.2 $(1: 5000)$ was added and after $1 \mathrm{~h}$ at $25^{\circ} \mathrm{C}$ the blots were washed with PBST-0.2. The immuno-complex was detected by nitro blue tetrazolium and 5-bromo-4-chloro-3indolylphosphate (Boehringer Mannheim).

ELISA of HSC70. For exact quantification of HSC70 in different developmental stages an indirect antibody capture assay was developed. The samples $(1 \mu \mathrm{g}$ total protein per well in $100 \mu \mathrm{l}$ coating buffer; $50 \mathrm{mM} \mathrm{Na}_{2} \mathrm{CO}_{3}, 50 \mathrm{mM} \mathrm{NaHCO}{ }_{3}, \mathrm{pH} 9.5$ ) or standards $(100 \mu \mathrm{l}$ coating buffer with $0-50 \mathrm{ng}$ purified N. crassa HSC70; Fracella et al., 1993) were loaded into polystyrene immuno plates (Maxisorb; Nunc). Standards were prepared by adding $10 \mathrm{mM}$ ATP and $10 \mathrm{mM} \mathrm{MgCl}$ to the stock solution. The covered plate was incubated overnight at $4{ }^{\circ} \mathrm{C}$. Coating efficiency of microtitre plates was assessed by the bicinchoninic acid protein determination kit (Pierce). The wells were emptied and blocked with $200 \mu \mathrm{l}$ PBST-0.05 (0.05\% Tween 20 in PBS, $\mathrm{pH} 7.5$ ) for $1 \mathrm{~h}$ at $25^{\circ} \mathrm{C}$ prior to washing three times with $200 \mu \mathrm{l}$ PBST-0.05. The affinity-purified polyclonal anti-HSC70 (1:1000 in PBST-0.05) was added in $100 \mu \mathrm{l}$ aliquots per well and incubated for $1 \mathrm{~h}$ at $25^{\circ} \mathrm{C}$ followed by three washes with $200 \mu$ l PBST-0.05. The amount of the primary antibody bound was determined by the addition of secondary antibody (goat anti-rabbit IgG alkaline phosphatase conjugate; Bio-Rad) at a dilution of $1: 2000$ in $100 \mu \mathrm{l}$ PBST-0.05 per well. The plate was emptied and washed three times with PBST and one time with substrate buffer $(1 \mathrm{M}$ diethanolamine, $10 \mathrm{mM} \mathrm{MgCl}, \mathrm{pH} 9 \cdot 7$ ). The activity of the bound phosphatase was measured by conversion of pNPP (4nitrophenyl-phosphate, Boehringer) to a chromogenic product. pNPP [ $1 \mathrm{mg}(\mathrm{ml} \text { substrate buffer })^{-1}$ ] was prepared just before addition of $100 \mu \mathrm{l}$ to each well. The amount of HSC70 present in the wells was given by the absorbance at $405 \mathrm{~nm}$ measured after $1 \mathrm{~h}$ reaction time in a 96-well plate computercontrolled kinetic plate reader (SLT), after correction for background absorbance $(690 \mathrm{~nm})$ in wells containing coating buffer alone. A single value is the mean of independent triplicates. In one experiment, the amount of HSC70 is expressed as an absolute quantity [ng HSC70 ( $\mu \mathrm{g}$ total protein $)^{-1}$ ] derived from a standard curve using purified $N$. crassa HSC70.

CAMP measurements. Aerial hyphae, mycelia and conidia from different developmental stages during the asexual cycle of $N$. crassa were frozen in liquid nitrogen. The freeze-dried samples were dissolved in $1.75 \%$ perchloric acid and homogenized by sonication. After neutralization with $50 \%$ saturated $\mathrm{K}_{2} \mathrm{CO}_{3}$ for $15 \mathrm{~min}$, the samples were centrifuged at $10000 \mathrm{~g}$ for $5 \mathrm{~min}$. The supernatant contains the cAMP. The cAMP content was determined by a ${ }^{3}[\mathrm{H}]$ cAMP proteinbinding assay from Amersham according to the manufacturer's instructions. As reference the dry weight of corresponding samples was determined; total protein measurements revealed similar cAMP values.

Analytical procedures. Protein concentration was determined according to the method of Neuhoff et al. (1979).

\section{RESULTS}

\section{Expression of HSC70 during asexual development}

Asexual development of $N$. crassa consists of the following main stages: dormant conidia (spores) which germinate when suspended in the appropriate medium (germinating conidia). Germination lasts about $6 \mathrm{~h}$ and leads to the formation of hyphae and a growing mycelium. When the medium is exhausted the mycelium enters the stationary state. In response to environmental challenges including desiccation, nutrient deprivation, 
(a)

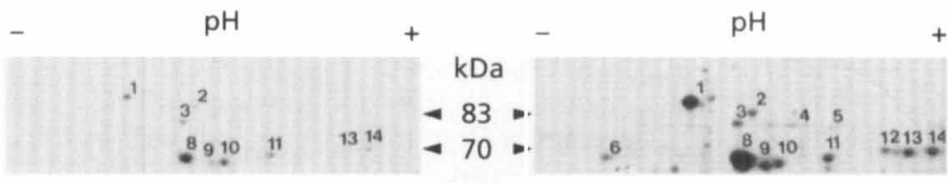

A

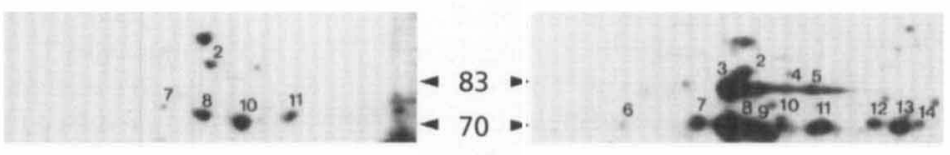

B

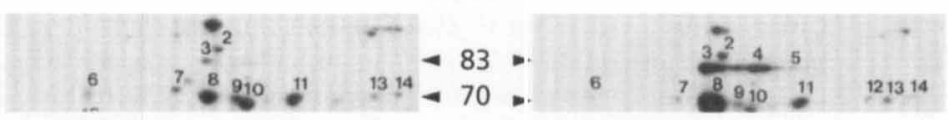

C

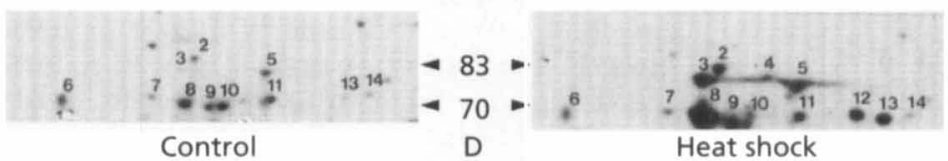

(b)
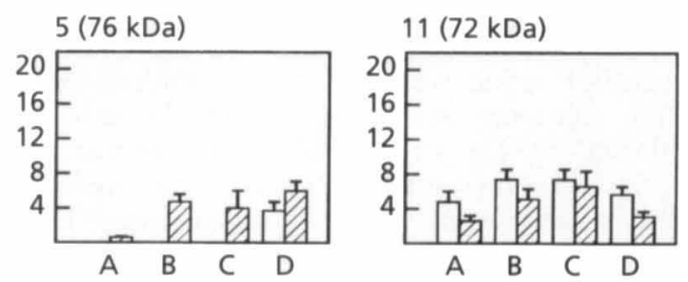

$8(72 \mathrm{kDa})$
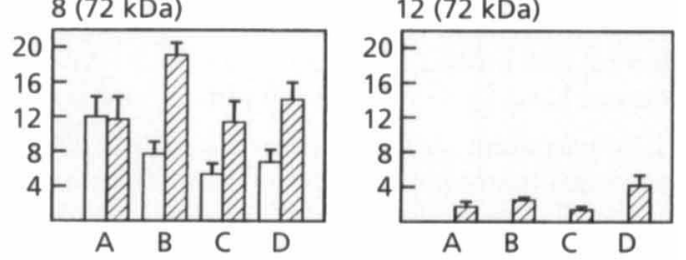

Fig. 1. Constitutive and induced synthesis of high molecular mass HSCs/HSPs at different stages of development (A germinating conidia; B, exponentially growing mycelia; C, stationary mycelia; D, aerial hyphae). (a) Two-dimensional gel electrophoresis after $1 \mathrm{~h}$ incubation with $\left[{ }^{35} \mathrm{~S}\right]$ methionine. Control $\left(25^{\circ} \mathrm{C}\right)$; heat shock $\left(1 \mathrm{~h}\right.$ at $\left.45^{\circ} \mathrm{C}\right)$. Arrows indicate the approximate molecular mass of the HSC/HSP90 (83 kDa) and $70(70 \mathrm{kDa})$ families; numbers designate individual spots. (b) Quantitative analysis of four individual spots at different stages of development [see (a)]. Control, open bars; heat shock, hatched bars. Means of three independent experiments \pm SD. Ordinate: density of the spot as a percentage of total density of 25 selected spots.

light (Ninnemann, 1991) and heat shock (G. Gebauer \& L. Rensing, unpublished), aerial hyphae and conidia are formed in a differentiation process lasting about $12-24 \mathrm{~h}$ (for a review see Russo \& Pandit, 1992).

First, HSC expression was analysed during germination, in exponential and stationary growth phase and during aerial hyphae development $(12 \mathrm{~h}$ after beginning of aerial hyphae formation, i.e. at an intermediate state of conidiation). The constitutive as well as the induced expression of the high-molecular-mass HSPs (76-83 $\mathrm{kDa}$ and $70 \mathrm{kDa}$, belonging to the HSP90 and HSP70 families respectively) was generally lower in germinating conidia and stationary-phase mycelia (Fig. $1 \mathrm{a}, \mathrm{A}, \mathrm{C})$ and higher during exponential growth and aerial hyphae development (Fig. 1a, B, D). This was particularly true for the induced synthesis of the major HSC70 (Fig. 1a, B, no. 8), an isoform which was previously characterized by Fracella et al. (1993) and Kapoor et al. (1995). The constitutive synthesis of this protein, however, was highest during conidial germination.

A particularly high constitutive expression during aerial hyphae development was observed for a $76 \mathrm{kDa}$ protein probably belonging to the heat shock protein 90 family (Fig. 1a, B, no. 5), and two proteins of $70 \mathrm{kDa}$ (nos 9 and 14). High induced synthesis was observed in aerial hyphae for two HSPs90 (Fig. 1a, B, nos 2 and 5) and three HSPs70 (Fig. 1a, B, nos 6, 9 and 12). One of this group of proteins $(72 \mathrm{kDa})$, which is not inducible, showed a high expression during stationary phase (Fig. 1a, B, no. 11).

To address the question of developmental changes of HSP expression in more detail and more quantitatively, extracts from dormant and germinating conidia, mycelia, young and old aerial hyphae were analysed by Western blotting, using a polyclonal antibody against the major HSC70 of N. crassa (Fracella et al., 1993). The results showed that dormant conidia contained the highest concentration of HSC70 compared to the other developmental stages (Fig. 2a). During conidial germination this level first decreased and again increased later during vegetative growth (Fig. 2a). Lowest constitutive HSC70 levels occurred in young aerial hyphae, and the level strongly increased in older and conidiating aerial hyphae (Fig. 2b). The changes in amount of HSC70 during the developmental stages were similar in both the wt and $b d$ strains. The amount of actin per unit amount of protein as determined densitometrically on Coomassie-Blue-stained SDS-polyacrylamide gels remained constant during the different developmental stages.

These stage-specific differences in the amount of HSC70 were confirmed by quantitative analysis using ELISA and purified N. crassa HSC70 (Fracella et al., 1993) as standard. The absolute amount of HSC70 was highest in dormant conidia, lower in exponentially growing my- 


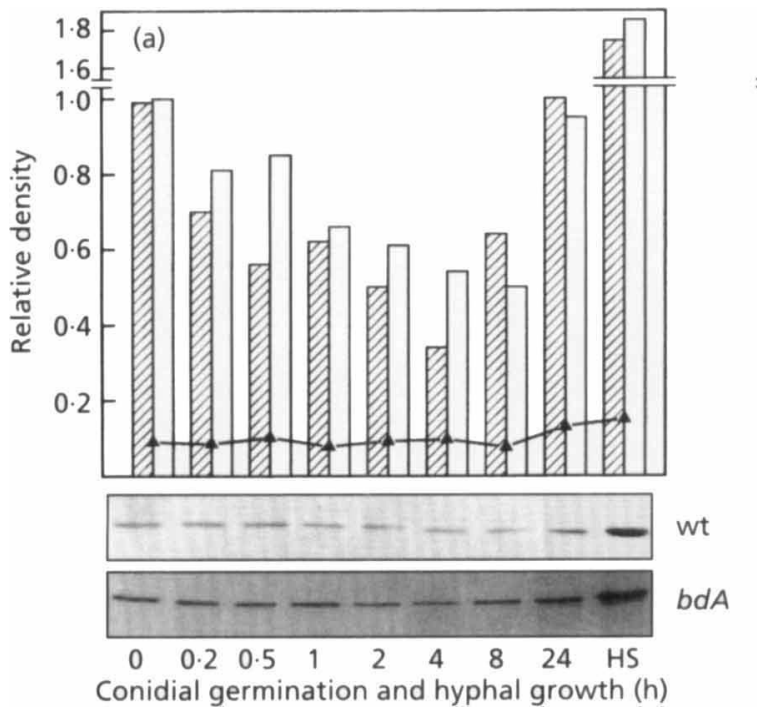

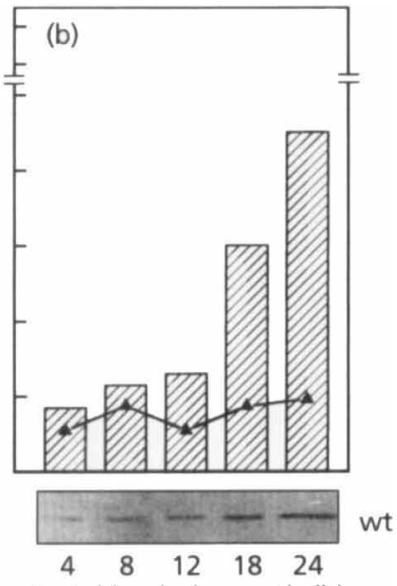

Aerial hyphal growth $(h)$
Fig. 2. Expression of $\mathrm{HSC70}$ during asexual development of the wild-type (wt) strain (hatched bars) and the $b d A$ mutant (open bars) of $N$. crassa. (a) Amounts of HSC70 in dormant $(\mathrm{Oh})$ and germinating conidia $(0.2-8 \mathrm{~h})$, in exponentially growing mycelia (24 h), and after heat shock (HS; $\left.45^{\circ} \mathrm{C}, 1 \mathrm{~h}\right)$. (b) Amounts of HSC70 in aerial hyphae and during conidiation of the wt strain (abscissa: time after first appearance of aerial hyphae; conidiation began after $12 \mathrm{~h}$ ). The densitometric measurement of HSC/HSP7O is shown above the Western blot images. The amounts of actin ( $\boldsymbol{\Delta}$ ) were evaluated densitometrically from Coomassie-bluestained SDS-PAGE gels.
Table 1. Total constitutive $\mathrm{HSC70}$ at different developmental stages and after heat shock (HS) of exponentially growing mycelia of the wild-type of $N$. crassa as determined by ELISA

Amount of HSC70 is expressed as $\mathrm{ng}$ ( $\mu \mathrm{g}$ total cellular protein) $)^{-1}( \pm S D)$ (means of three independent determinations).

\begin{tabular}{|ll|}
\hline & HSC70 \\
\hline Conidia (dormant) & $34( \pm 4)$ \\
Conidia (1 h activated) & $26( \pm 5)$ \\
Conidia (4 h activated) & $30( \pm 3)$ \\
Aerial hyphae $(6 \mathrm{~h})$ & $11( \pm 2)$ \\
Aerial hyphae $(24 \mathrm{~h})$ & $33( \pm 3)$ \\
Exponential mycelium $(24 \mathrm{~h})$ & $31( \pm 3)$ \\
Exponential mycelium $(40 \mathrm{~h})$ & $29( \pm 3)$ \\
Exponential mycelium $\left(24 \mathrm{~h} ; \mathrm{HS}, 1 \mathrm{~h}, 45^{\circ} \mathrm{C}\right)$ & $52( \pm 6)$ \\
Stationary mycelium $(70 \mathrm{~h})$ & $25( \pm 3)$ \\
\hline
\end{tabular}

celium, still lower in stationary mycelium, and lowest in young aerial hyphae. The amount increased again in old aerial hyphae (Table 1).

To relate the amount of HSC70 to the growth phase of the mycelium more precisely, changes in dry weight of the cultures were measured as an indicator of the growth phase as well as the total cytoplasmic and nuclear HSC70 levels. During growth to stationary phase the amount of HSC70 decreased in total cell homogenates and the cytoplasmic fraction. However, HSC70 content increased in the nuclear fraction (Fig. 3).

Because the nuclear localization of HSC70 might affect HSF activity and hence the transcription of HSCs, the amount of nuclear HSC70 was analysed during different stages of aerial hyphae development. During these stages the amounts of the constitutive (HSC70) and inducible (HSP70) isoforms in the cytoplasmic and nuclear frac-
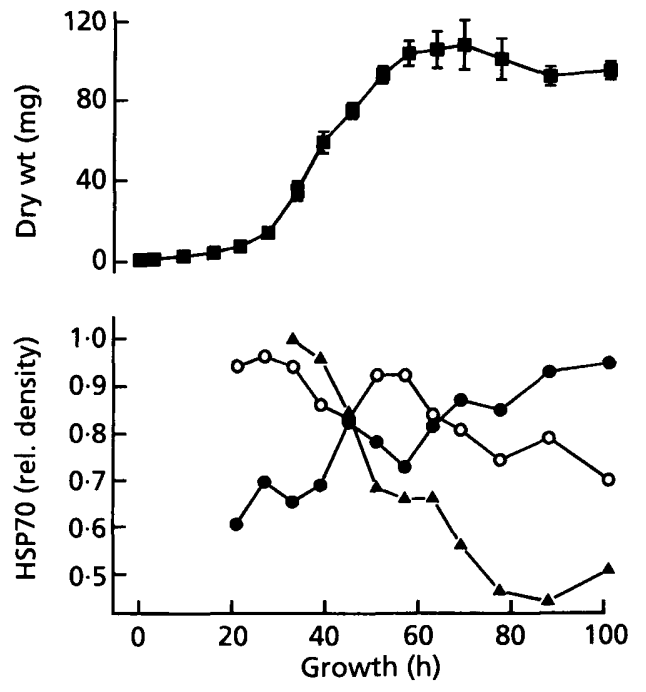

Fig. 3. Cytoplasmic, nuclear and total HSC70 levels of the $b d A$ mutant of $N$. crassa during growth to stationary phase. The bdA mutant was cultured at $25^{\circ} \mathrm{C}$ for the indicated times. The growth curve calculated from the dry weight increase is presented in the upper part of the graph (means of three independent experiments). The mycelia were fractionated $(O$, total homogenate; $\boldsymbol{\Delta}$, cytoplasmic; $\boldsymbol{\theta}$, nuclear fraction), HSC70 was analysed by means of Western blotting, densitometrically evaluated and expressed as relative density. The highest density from each blot was designated as 1.0 (means of three independent experiments).

tion were also determined after a $1 \mathrm{~h}$ exposure at $45^{\circ} \mathrm{C}$. The results also showed that constitutive expression rises from the early ( $4 \mathrm{~h})$, to medium $(8 \mathrm{~h})$ to late $(12 \mathrm{~h})$ stages, up to particularly high values at the very late (24 h) stage (Fig. 4). The same increase was observed but at a higher level after heat shock, which demonstrates increasing inducibility of HSP and HSC70 isoforms during aerial hyphae development. The amounts of HSC/HSP70 in the nucleus, however, remained rather 

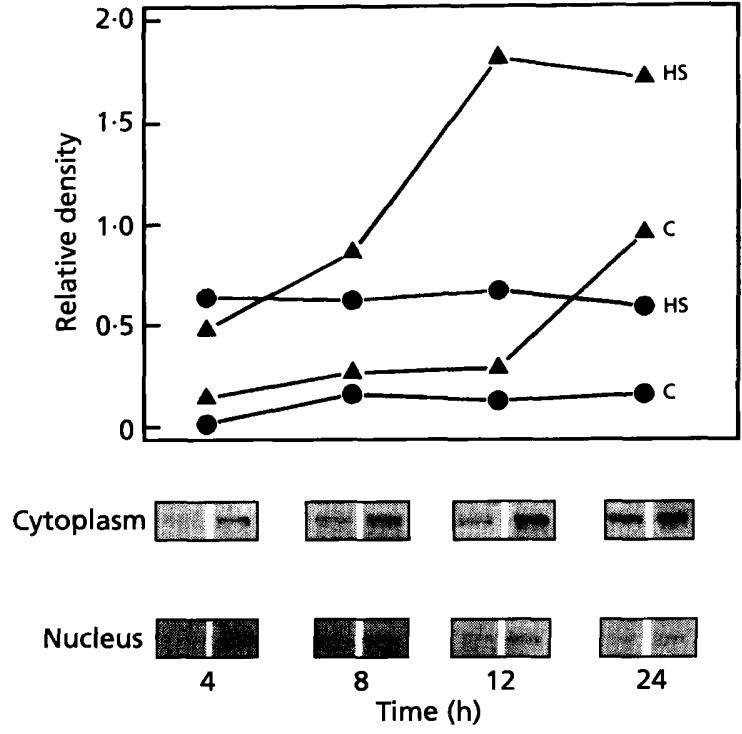

Fig. 4. Constitutive and heat-shock-induced HSC/HSP7O levels in the cytoplasm and nucleus during aerial hyphae development. $\Delta$. Cytoplasmic fraction; O, nuclear fraction; C, control (at $\left.25^{\circ} \mathrm{C}\right)$; HS, heat-shocked samples $\left(1 \mathrm{~h}\right.$ at $\left.45^{\circ} \mathrm{C}\right)$. Ordinate: relative units, highest constitutive density taken as 1.0; abscissa: age of aerial hyphae in $\mathrm{h}$. At each time, Western blots of control (left) and heat-shocked (right) samples are shown.

constant during this period. Therefore, these results do not support a regulatory role of nuclear HSC70.

\section{CAMP content during asexual development}

To elucidate a possible role of cAMP in the developmental regulation of HSC70, the cAMP content was determined at different developmental stages of the $b d$ strain. Total dry weight was used as a reference value, because other standards such as the amount of total protein produced similar results. The data revealed a significant increase from dormant to germinating conidia (about fivefold between 0 and 6 h, Fig. 5a). Thereafter, the level decreased again with increasing age of the growing and stationary mycelium. The young aerial hyphae $(6 \mathrm{~h}$ after beginning of aerial hyphae formation) showed the highest cAMP content, which then declined in older aerial hyphae to less than about $20 \%$ of the initial values in conidiating aerial hyphae. Except for growth to stationary phase, these developmental changes in cAMP content showed a strong inverse correlation to the changes of the HSC70 level (Fig. 5b).

\section{Effects of CAMP on HSP70 expression}

To test a possible causal relation between cAMP content and the expression of constitutive HSC70 in growing hyphae, the adenylate-cyclase-deficient mutant $c r-1$ with low cAMP content (Terenzi et al., 1974) was compared to the $b d$ strain with respect to the amount of HSC70. cAMP determinations confirmed that the cAMP content
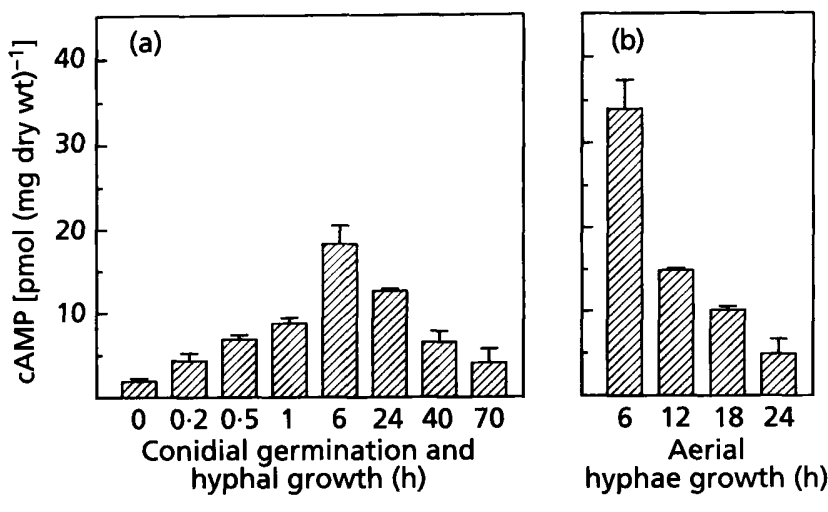

Fig. 5. CAMP content during asexual development of the $b d A$ mutant of $N$. crassa. (a) Amount of CAMP in dormant $(0 \mathrm{~h})$ and germinating conidia $(0.2-8 \mathrm{~h})$, in exponential growing mycelia $(24 \mathrm{~h})$, and during growth to the stationary phase (40 and $70 \mathrm{~h})$ (means of three independent experiments $\pm S D$ ). (b) Amounts of CAMP in aerial hyphae and during conidiation of the $b d A$ mutant (abscissa: time after first appearance of aerial hyphae; conidiation began after $12 \mathrm{~h}$ ) (means of three independent experiments $\pm \mathrm{SD}$ ).

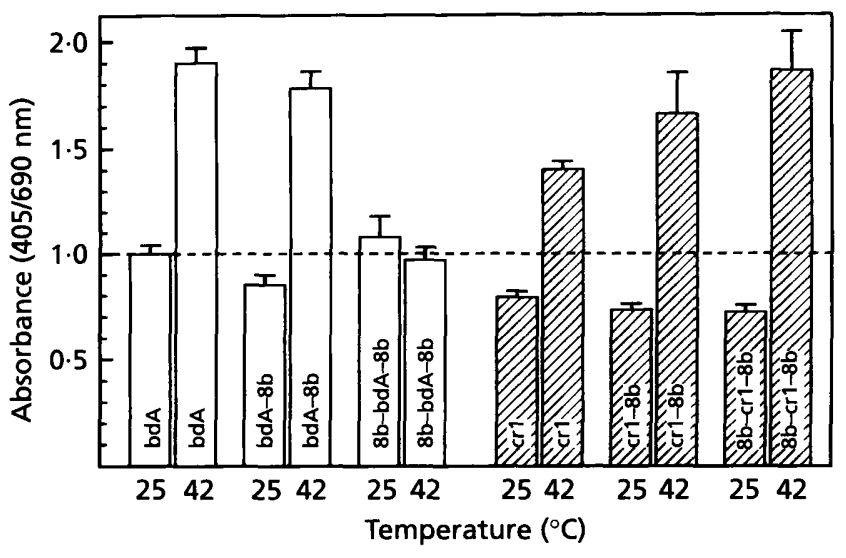

Fig. 6. Effects of 8-bromo-CAMP $(20 \mu \mathrm{M})$ on the expression of $\mathrm{HSC} / \mathrm{HSP} 70$ in growing mycelia of $b d A$ and $\mathrm{cr}-1$ determined by means of three independent ELISA measurements \pm SD. $25^{\circ} \mathrm{C}=$ constitutive expression; $42{ }^{\circ} \mathrm{C}=$ induced expression after $1.25 \mathrm{~h}$ exposure to $42^{\circ} \mathrm{C}$. bdA-8b, $\mathrm{Cr} 1-8 \mathrm{~b}=$ incubation of the two strains with $20 \mu \mathrm{M}$ 8-bromo-CAMP from germination to exponential growth; 8b-bd-A-8b, 8b-cr1-8b = incubation with 8-bromo-cAMP during growth and during the preceding growth period (see Methods). Vertical broken line: common reference (constitutive HSC70) to which the other values were related (ordinate). The absorption ratio was always determined in probes of $1 \mu \mathrm{g}$ total protein.

of the $c r-1$ mutant was, indeed, low $[0 \cdot 61 \pm 0 \cdot 15 \mathrm{pmol}$ $(\mathrm{mg} \text { dry weight })^{-1}$ during exponential growth as compared to $6 \cdot 12 \pm 0.88 \mathrm{pmol}(\mathrm{mg} \text { dry weight })^{-1}$ in the wtand in the $b d \bar{A}$ strain].

During exponential growth the HSC70 level in the $c r-1$ mutant was lower than that in the $b d A$ strain (Fig. 6). This disproved the assumption of an inverse causal relationship between cAMP content and amount of 
constitutive HSC70. That the constitutive amount of HSC70 is not affected by cAMP was further confirmed by incubation experiments: when the $b d A$ and $c r-1$ strains were grown in the presence of $20 \mu \mathrm{M}$ 8-bromocAMP, the constitutive HSC70 level remained almost constant (Fig. 6). During aerial hyphae formation and conidiation the increase in HSC70 was also not influenced by the presence of $20 \mu \mathrm{M} 8$-bromo-cAMP (data not shown).

Further experiments were performed to test whether cAMP might affect heat-induced HSP70 expression. Firstly, Western blot analysis was carried out to characterize the increase of HSP70 in response to heat shock. Heat shock enhanced the amount of HSP70 depending on the temperature increase. In vegetative hyphae of the $b d A$ mutant, the lowest temperature step resulting in a significantly enhanced HSP70 level is a shift from 25 to $37^{\circ} \mathrm{C}$ applied for $1 \mathrm{~h}$. Exposure to 41,43 or $45^{\circ} \mathrm{C}$ for $1 \mathrm{~h}$ induced maximal amounts, whereas $1 \mathrm{~h}$ heat shock of $47^{\circ} \mathrm{C}$ resulted in lower HSP70 induction, perhaps due to a loss of cell viability (data not shown). The following experiment, therefore, used a heat shock of $42{ }^{\circ} \mathrm{C}$ for $1 \mathrm{~h}$.

The induced expression of HSP70 was significantly lower in the $c r-1$ mutant than in $b d$. However, in contrast to the effect on constitutive expression, the continuous presence of $20 \mu \mathrm{M} 8$-bromo-cAMP increased the heat-induced amount of HSP70 in the $c r-1$ mutant and decreased it in the $b d A$ strain (Fig. 6). This result may be explained by an optimum cAMP content for the induction of HSP70 which is represented by the cAMP value during exponential growth. This assumption may also explain the low induction of HSP70 in young aerial hyphae, when the cAMP content is high. Whether this effect of cAMP represents a direct or indirect influence on the induced HSP70 synthesis remains unclear.

\section{Developmental steps}

The development-dependent expression of HSC70 may be due to differentiation-specific changes in the cells. To test this possibility the amounts of HSC70 during aerial hyphae differentiation were analysed in a developmental mutant of $N$. crassa. In this mutant an early step during differentiation - the minor constriction budding - is defective (acon-2 mutant; Roberts et al., 1988; Springer \& Yanofsky, 1989). In acon-2, conidiation is strongly reduced at $25^{\circ} \mathrm{C}$ ( $\mathrm{T}$. Häfker, unpublished experiments) and blocked at higher temperatures.

When HSC70 expression was analysed in the particularly long aerial hyphae of the acon- 2 strain the HSC70 amounts remained low during at least $48 \mathrm{~h}$, at which age the other strains already attained high levels. Only after $72-84 \mathrm{~h}$ was an increase of HSC70 content observed together with the appearance of proconidial chains (data not shown). This result suggests a coupling between morphogenetic steps (conidia formation) and increased expression of HSCs.

\section{DISCUSSION}

Within the high-molecular-mass HSP families (HSP/ HSC90 and 70), two isoforms can be distinguished: one is synthesized constitutively and also called heatshock cognate (HSC), the other is synthesized predominately during or after stress (HSP). The constitutive forms are often moderately enhanced by stress (Becker \& Craig, 1994). The expression of both forms can change during developmental processes (for a review see Hightower \& Nover, 1991). In N. crassa, two-dimensional gel electrophoresis showed that this is the case during asexual development: generally, the constitutive and induced synthesis of members of the HSC/HSP90 and 70 families were highest during exponential growth and aerial hyphae development and lower in germinating conidia and stationary mycelia. Western blot analysis, using a polyclonal antibody against the major HSC70 of $N$. crassa, revealed different amounts of HSC70 during the asexual development of $N$. crassa with highest HSC70 amounts in conidiating aerial hyphae and dormant conidia.

Whether higher amounts of HSC70 are required in the conidia forming process or whether aerial hyphae provide conidia with HSC70 is not known. In dormant conidia, the high concentration of HSC70 may be responsible for their resistance to a variety of environmental stressors and desiccation. A similar speculation about plant seeds has been advanced by Wang \& Lin (1993) and Coca et al. (1994). On the other hand, HSC70 is known to be involved in the correct folding of newly synthesized proteins (Hartl et al., 1994) and therefore may be important in the early conidial germination. High amounts of HSC70 during this stage of N. crassa development are provided by storage (Fig. 2) and de novo synthesis (Fig. 1A, B, no. 8). HSC70 also facilitates the degradation of certain proteins (Dice et al., 1994) and may thus be involved in the degradation of storage proteins in early-germinating conidia as was observed in plant seeds (Wang \& Lin, 1993).

In $S$. cerevisiae, sporulation results in higher HSC expression (Kurtz \& Lindquist, 1984; WernerWashburne et al., 1989). Conversely, differentiation and sporulation in Neurospora are triggered by stressful events such as starvation, aeration (Nelson et al., 1975; Toledo et al., 1995) or heat shock itself (G. Gebauer \& L. Rensing, unpublished).

An inverse correlation between the HSC70 levels and cAMP content during most developmental stages of $N$. crassa was observed in this study. These results are supported by other findings, which suggested that cAMP plays a role in the sporulation of lower eukaryotes and may influence the synthesis of certain HSCs. Mutants of $S$. cerevisiae altered in cAMP-dependent protein phosphorylation show altered sporulation capacity (Matsumoto et al., 1983) and heat-shock responses (Shin et al., 1987). The bcy1 mutant, which shows a constitutively active cAMP-dependent protein kinase (cPKA) did not synthesize the major HSPs in response to stress and failed to acquire thermotolerance (Shin et al., 
1987; Matsumoto et al., 1983). These phenotypes can be rescued by mutations which attenuate the catalytic properties of the cPKA (Cameron et al., 1988). In contrast, the cyr1-2 mutants, which can produce only low amounts of cAMP, constitutively synthesize high levels of HSPs, and are more resistant to heat treatment (Shin et al., 1987; Matsumoto et al., 1983).

Like the cyr1-2 mutants of $S$. cerevisiae, the $c r-1$ mutant of $N$. crassa shows constitutive thermotolerance and exhibits some morphological changes (Terenzi et al., 1974). These phenotypes are partially reversed by the addition of external cAMP (Cruz et al., 1988). Boorstein \& Craig (1990) identified a CRE in the promoter of the SSA3 (HSC70) gene of $S$. cerevisiae. In conjunction with the adjacent HSE the CRE was found to regulate SSA3 expression after the diauxic shift and in stationary phase. Reduced cAMP-dependent protein kinase (cPKA) activity resulted in CRE-dependent SSA3 expression. In our analysis of the constitutive expression of the major HSC70 of N. crassa, however, we did not observe an influence of cAMP. Whether the lower induction of HSP70 in the $b d$ strain and the higher induction of HSP70 in $c r-1$ mutants after long exposures of exogenous cAMP represent direct effects is not clear. The results may indicate the existence of an optimum concentration of CAMP for maximal HSP70 induction. However, short-term exposures to different exogenous cAMP concentrations had no influence on the induced amounts of $h s p 70 \mathrm{mRNA}$ (T. Häfker, unpublished experiments).

HSC70 is believed to have important functions in the nuclear import of other proteins (Shi \& Thomas, 1992), such as certain transcription factors (Moreau et al., 1994). On the other hand, HSC/HSP70 have been suggested to be involved in the inhibition of HSF activity, because under certain conditions the binding of HSF to DNA can be uncoupled from the acquisition of transcriptional activity (Hensold $e t$ al., 1990; Bruce et al., 1993; Jurivich et al., 1992). Wu and co-workers showed that the interaction of HSF and HSP70 is insufficient to suppress the induction of DNA-binding activity (Rabindran et al., 1994). However, the deactivation of HSF to the non-DNA-binding state seems to be accelerated by HSP70 (Rabindran et al., 1994; Kim et al., 1995). In Neurospora, the HSF is apparently located mainly in the nucleus (U. Meyer, unpublished). However, our attempt to relate the nuclear localization of HSC70 to HSC70 expression, failed: except for the stationary state, there was no such correlation during aerial hyphae development.

The only relation supported by the experiments reported here is that between higher constitutive HSC70 as well as induced HSP70 synthesis and conidia formation. In acon-2, both the beginning of conidiation and the higher expression of HSC70 is delayed at $25^{\circ} \mathrm{C}$, suggesting a common trigger for the two processes. The mechanisms behind this coupling are not clear.

When the expression of other members of the $h s p 70$ gene family (for example: $g r p 78$ ) was examined during aerial hyphae development by Northern blot analysis (T. Häfker, unpublished), the constitutive and induced expression of $g r p 78$ increased drastically with the progress of conidia formation in a similar fashion as reported here for HSC70. Again, the expression of this gene was not influenced by $20 \mu \mathrm{M} 8$-bromo-cAMP ( $\mathrm{Ch}$. Monnerjahn, unpublished) and low in late ( $24 \mathrm{~h})$ aerial hyphae of the acon-2 mutant.

The results reported here demonstrate a drastic increase in the expression of constitutive and-after inductive treatments - of inducible heat-shock genes in the course of conidiation. The biological significance may be seen in the folding and translocation of newly synthesized proteins during conidium formation. Most important is probably a storage of HSCs for the protection of other proteins and for securing high chaperone availability during germination of conidia. A controlling mechanism for the differential HSC/HSP70 expression may be coupled to differentiation steps.

\section{ACKNOWLEDGEMENTS}

We thank Michael G. Vicker for his critical reading of the manuscript. The work was supported by a grant from the Stiftung Volkswagenwerk to one of us (A.K.).

\section{REFERENCES}

Becker, J. \& Craig, E. A. (1994). Heat-shock proteins as molecular chaperones. Eur J Biochem 219, 11-23.

Bienz, M. \& Pelham, H. R. B. (1987). Mechanisms of heat shock activation in higher eukaryotes. Adv Genet 24, 31-72.

Bonato, M. C., Silvia, A. M., Gomes, S. L., Maia, J. C. \& Juliani, M. H. (1987). Differential expression of heat shock proteins and spontaneous synthesis of HSP70 during the life cycle of Blastocladiella emersonii. Eur J Biochem 163, 211-220.

Bonner, W. M. \& Laskey, R. A. (1974). A film detection method for tritium-labelled proteins and nucleic acids in polyacrylamide gels. Eur J Biochem 46, 83-88.

Boorstein, W. R. \& Craig, E. A. (1990). Regulation of a yeast HSP70 gene by a cAMP responsive transcriptional control element. EMBO J 9, 2543-2553.

Bruce, J. L., Price, B. D., Coleman, C. N. \& Calderwood, S. K. (1993). Oxidative injury rapidly activates the heat shock transcription factor but fails to increase levels of heat shock proteins. Cancer Res 53, 12-15.

Cameron, S., Levin, L., Zooler, M. \& Wigler, M. (1988). cAMPindependent control of sporulation, glycogen metabolism, and heat shock resistance in Saccharomyces cerevisiae. Cell 53, 555-566.

Choi, H.-S., Li, B., Lin, Z., Huang, E. \& Liu, A. Y.-C. (1991). cAMP and cAMP-dependent protein kinase regulate the human heat shock protein 70 gene promoter activity. J Biol Chem 266, 11858-11865.

Coca, M. A., Almoguera, C. \& Jordano, J. (1994). Expression of sunflower low-molecular-weight heat-shock proteins during embryogenesis and persistence after germination: localization and possible functional implications. Plant Mol Biol 25, 479-492.

Cruz, A. K., Terenzi, H. F., Jorge, J. A. \& Terenzi, H. F. (1988). Cyclic AMP-dependent, constitutive thermotolerance in the adenylate cyclase-deficient $c r-1$ (crisp) mutant of Neurospora crassa. Curr Genet 13, 451-454. 
Dice, J. F., Agarraberes, F., Kirven-Brooks, M., Terlecky, L. J. \& Terlecky, S. R. (1994). Heat shock $70-k D$ proteins and lysosomal proteolysis. In The Biology of Heat Shock Proteins and Molecular Chaperones, pp. 137-152. Edited by R. I. Morimoto, A. Tissieres \& C. Georgopoulos. Cold Spring Harbor, NY: Cold Spring Harbor Laboratory.

Engelberg, D., Zandi, E., Parker, C. S. \& Karin, M. (1994). The yeast and mammalian Ras pathway control transcription of heat shock genes independently of heat shock transcription factor. Mol Cell Biol 14, 4929-4937.

Fracella, F., Mohsenzadeh, S. \& Rensing, L. (1993). Purification and partial amino acid sequence of the major 70,000-Dalton heat shock protein in Neurospora crassa. Exp Mycol 17, 362-367.

Giardina, C. \& Lis, J. T. (1995). Dynamic protein-DNA architecture of a yeast heat shock promoter. Mol Cell Biol 15, 2737-2744.

Hartl, F.-U., Hlodan, R. \& Langer, T. (1994). Molecular chaperones in protein folding: the art of avoiding sticky situations. Trends Biochem Sci 19, 20-25.

Hensold, J. O., Hunt, C. R., Calderwood, S. K., Housman, D. E. \& Kingston, R. E. (1990). DNA binding of heat shock factor to the heat shock element is insufficient for transcriptional activation in murine erythroleukemia cells. Mol Cell Biol 10, 1600-1608.

Hightower, L. \& Nover, L. (editors) (1991). Results and Problems in Cell Differentiation: Heat Shock and Development. Heidelberg: Springer.

Horowitz, N. H. (1947). Methionine synthesis in Neurospora. The isolation of cystathionine. J Biol Chem 171, 255-264.

lida, H. \& Yahara, I. (1984). A heat shock-resistant mutant of Saccharomyces cerevisiae shows constitutive synthesis of two heat shock proteins and altered growth. J Cell Biol 99, 1441-1450.

Jurivich, D., Sistonen, L., Kroes, R. \& Morimoto, R. I. (1992). Effect of sodium salicylate on the human heat shock response. Science 255, 1243-1245.

Kapoor, M., Curle, C. A. \& Runham, C. (1995). The $h s p 70$ gene family of Neurospora crassa: cloning, sequence analysis, expression, and genetic mapping of the major stress-inducible member. J Bacteriol 177, 212-221.

Kiang, J. G., Carr, F. E., Burns, M. E. \& McClain, D. E. (1994). HSP72 synthesis is promoted by increase in $\left[\mathrm{Ca}^{2+}\right]_{\mathrm{i}}$ or activation of $\mathrm{G}$ proteins but not $\mathrm{pH}_{\mathrm{i}}$ or cAMP. Am J Physiol 267, C104-C114.

Kim, D., Ouyang, H. \& Li, G. C. (1995). Heat shock protein Hsp70 accelerates the recovery of heat-shocked mammalian cells through its modulation of heat shock transcription factor HSF1. Proc Natl Acad Sci USA 92, 2126-2130.

Kurtz, S. \& Lindquist, S. (1984). Changing patterns of gene expression during sporulation in yeast. Proc Natl Acad Sci USA 81, 7323-7327.

Laemmli, U. K. (1970). Cleavage of structural proteins during the assembly of the head of bacteriophage T4. Nature 227, 680-685.

Liu, R. Y., Kim, D., Yang, S. H. \& Li, G. C. (1993). Dual control of heat shock response: involvement of a constitutive heat shock element-binding factor. Proc Natl Acad Sci USA 90, 3078-3082.

Loros, J. J. \& Dunlap, J. C. (1991). Neurospora crassa clockcontrolled genes are regulated at the level of transcription. Mol Cell Biol 11, 558-563.

Machwe, A. \& Kapoor, M. (1993). Identification of the heat shock protein of Neurospora crassa corresponding to the stressinducible peroxidase. Biochem Biophys Res Commun 196, 692-698.

Matsumoto, K., Uno, I. \& Ishikawa, T. (1983). Initiation of meiosis in yeast mutants defective in adenylate cyclase and cyclic AMPdependent protein kinase. Cell 32, 417-423.

Matsuyama, S. S., Nelson, R. E. \& Siegel, R. W. (1974). Mutations specifically blocking differentiation of macroconidia in Neurospora crassa. Dev Biol 41, 278-287.

Moreau, N., Lain, M.-C., Billoud, B. \& Angelier, N. (1994). Transcription of amphibian lampbrush chromosomes is disturbed by microinjection of HSP70 monoclonal antibodies. Exp Cell Res 211, 108-114.

Morimoto, R. I., Sarge, K. D. \& Abravaya, K. (1992). Transcriptional regulation of heat shock genes. J Biol Chem 267, 21987-21990.

Morimoto, R. I., Tissieres, A. \& Georgopoulos, C. (editors). (1994). The Biology of Heat Shock Proteins and Molecular Chaperones. Cold Spring Harbor, NY: Cold Spring Harbor Laboratory.

Nelson, R. E., Selitrennikoff, C. P. \& Siegel, R. W. (1975). Cell changes in Neurospora. In Results and Problems in Cell Differentiation: Cell Cycle and Cell Differentiation, pp. 291-310. Edited by J. Reinert \& $\mathrm{H}$. Holzer. Heidelberg: Springer.

Neuhoff, V., Philipp, K., Zimmer, H. G. \& Mesecke, S. (1979). A simple, versatile, sensitive and volume-independent method for quantitative protein determination which is independent of other external influences. Hoppe-Seyler's Z Physiol Chem 360, $1657-1670$.

Ninnemann, H. (1991). Photostimulation of conidiation in mutants of Neurospora crassa. Photochem Photobiol B-Biol 9, 189-199.

O'Farrell, P. H. (1975). High resolution two-dimensional electrophoresis of proteins. J Biol Chem 250, 4007-4021.

Patterson, N. A. \& Kapoor, M. (1995). Developmentally regulated expression of heat shock genes in Leptosphaeria maculans. Can J Biochem 41, 499-507.

Pizurki, L. \& Polla, B. (1994). cAMP modulates stress protein synthesis in human monocytes-macrophages. J Cell Physiol 161, 169-177.

Plesofsky-Vig, N. \& Brambl, R. (1985a). The heat shock response of Neurospora crassa: protein synthesis and induced thermotolerance. J Bacteriol 162, 1083-1091.

Plesofsky-Vig, N. \& Brambl, R. (1985b). The heat shock response of fungi. Exp Mycol 9, 187-194.

Plesofsky-Vig, N. \& Brambl, R. (1990). Gene sequence and analysis of hsp30, a small heat shock protein of Neurospora crassa which associates with mitochondria. J Biol Chem 265, 15432-15440.

Rabindran, S. K., Wisniewski, J., Li, L., Li, G. C. \& Wu, C. (1994). Interaction between heat shock factor and $\mathrm{Hsp} 70$ is insufficient to suppress induction of DNA-binding activity in vivo. Mol Cell Biol 14, 6552-6560.

Roberts, A., Berlin, V., Hager, K. M. \& Yanofsky, C. (1988). Molecular analysis of a Neurospora crassa gene expressed during conidiation. Mol Cell Biol 8, 2411-2418.

Roychowdhury, H. S., Wong, D. \& Kapoor, M. (1992). hsp80 of Neurospora crassa: cDNA cloning, gene mapping, and studies of mRNA accumulation under stress. Biochem Cell Biol 70, 1356-1367.

Russo, V. E. A. \& Pandit, N. N. (1992). Development in N. crassa. In Development - the Molecular Genetic Approach, pp. 88-102. Edited by V. E. A. Russo, S. Brody, D. Cove \& S. Ottolenghi. Heidelberg: Springer.

Shi, Y. \& Thomas, J. O. (1992). The transport of proteins into the nucleus requires the 70 -kilodalton heat shock protein or its cytosolic cognate. Mol Cell Biol 12, 2186-2192. 
Shin, D.-Y., Matsumoto, K., lida, H., Uno, I. \& Ishikawa, T. (1987). Heat shock response of Saccharomyces cerevisiae mutants altered in cyclic AMP-dependent protein phosphorylation. Mol Cell Biol 7, 244-250.

Sorger, P. K. \& Pelham, H. R. B. (1988). Yeast heat shock factor is an essential DNA-binding protein that exhibits temperaturedependent phosphorylation. Cell 54, 855-864.

Sorger, P. K., Lewis, M. J. \& Pelham, H. R. B. (1987). Heat shock factor is regulated differently in yeast and HeLa cells. Nature 329, 81-84.

Springer, M. \& Yanofsky, C. (1989). A morphological and genetic analysis of conidiophore development in Neurospora crassa. Genes Dev 3, 559-571.

Terenzi, H., Flawia, M. \& Torres, H. (1974). A Neurospora crassa morphological mutant showing reduced adenylate cyclase activity. Biochem Biophys Res Commun 58, 990-996.

Toledo, I., Rangel, P. \& Hansberg, W. (1995). Redox imbalance at the start of each morphogenetic step of Neurospora crassa conidiation. Arch Biochem Biophys 319, 519-524.

Towbin, H., Staehelin, T. M. \& Gordon, J. (1979). Electrophoretic transfer of proteins from polyacrylamide gels to nitrocellulose sheets: procedure and some applications. Proc Natl Acad Sci USA 76, $4350-4354$.
Vassilev, A. O., Plesofsky-Vig, N. \& Brambl, R. (1992). Isolation, partial amino acid sequence, and cellular distribution of heatshock protein Hsp98 from Neurospora crassa. Biochim Biophys Acta 1156, 1-6.

Vogel, H. J. (1956). A convenient growth medium for Neurospora (medium M). Microb Genet Bull 13, 42-43.

Wang, C. \& Lin, B. L. (1993). The disappearance of an HSC70 species in mung bean seed during germination: purification and characterization of the protein. Plant Mol Biol 21, 317-329.

Werner-Washburne, M., Becker, J., Kosic-Smithers, J. \& Craig, E. A. (1989). Yeast HSP70 RNA levels vary in response to the physiological status of the cell. J Bacteriol 171, 2680-2688.

Williams, G. T., McClanahan, T. L. \& Morimoto, R. I. (1989). E1a transactivation of the human HSP70 promoter is mediated through the basal transcriptional complex. Mol Cell Biol 9, 2574-2587.

Wu, B. J., Kingston, R. E. \& Morimoto, R. I. (1987). Detection of three protein binding sites in the serum-regulated promoter of the human gene encoding the $70-\mathrm{kDa}$ heat shock protein. Proc Natl Acad Sci USA 84, 2203-2207.

Received 24 February 1997; revised 19 June 1997; accepted 15 July 1997. 